\title{
Social suppression of reproduction in male naked mole-rats, Heterocephalus glaber
}

\author{
C. G. Faulkes, D. H. Abbott and J. U. M. Jarvis* \\ MRC/AFRC Comparative Physiology Research Group, Institute of Zoology, Zoological Society \\ of London, Regent's Park, London NWI 4RY, UK; and *Department of Zoology, University of \\ Cape Town, Rondebosch, 7700 South Africa
}

Summary. To investigate possible anatomical and endocrine differences between breeding and non-breeding male naked mole-rats, 113 animals from 24 captive and 4 wild colonies were studied.

While breeding males had larger reproductive tract masses compared to non-breeders relative to body mass $(P<0.01)$, spermatogenesis was active in all of the non-breeding males examined histologically $(n=9)$ and spermatozoa were present in the epididymides. Compared with non-breeders, breeding males had significantly higher urinary testosterone concentrations (mean \pm s.e.m.: $23.8 \pm 2.3$ vs $5.2 \pm 1.4 \mathrm{ng} / \mathrm{mg}$ Cr respectively; $P<0.001)$, and plasma LH $(10.7 \pm 1.7$ vs $5.0 \pm 0.8 \mathrm{mi} . \mathrm{u} . / \mathrm{ml}$ respectively; $P<0.01)$. Single doses of $0.1,0.5$ or $1.0 \mu \mathrm{g} \mathrm{GnRH}$ produced a significant rise in plasma $\mathrm{LH}$ concentrations $20 \mathrm{~min}$ after s.c. injection in breeding and non-breeding males at all doses $(P<0.001)$. However, there were differences in the magnitude of the LH response following administration of GnRH between breeding and non-breeding males, with non-breeding males showing a dose-response and having lower plasma $\mathrm{LH}$ concentrations 20 min after a single injection of 0.1 or $0.5 \mu \mathrm{g}(P<0.05)$, but not $1.0 \mu \mathrm{g}$, $\mathrm{GnRH}$. This apparent lack of pituitary sensitivity of non-breeding males to single doses of exogenous GnRH was reversed by 4 consecutive injections of $0.5 \mu \mathrm{g} \mathrm{GnRH}$ at hourly intervals, suggesting that the reduced sensitivity may be the result of insufficient priming of the pituitary by endogenous $\mathrm{GnRH}$.

These results indicate that, despite the fact that non-breeding males were apparently producing mature gametes, clear endocrine deficiencies existed in male naked mole-rats.

Keywords: reproductive suppression; naked mole-rats; hystricomorph rodent; testosterone; LH

\section{Introduction}

Colonies of naked mole-rats, Heterocephalus glaber, a subterranean hystricomorph rodent inhabiting the arid regions of East Africa, including Kenya, Ethiopia and Somalia, commonly contain 40-90 individuals (Brett, 1986, 1991; Jarvis, 1985). Living entirely underground, their burrow systems contain communal nest and toilet chambers, and an extensive network of foraging tunnels, which may total 2-3 km in length (Brett, 1986, 1991). Apart from having a behavioural division of labour similar to that of the eusocial insects (Jarvis, 1981; Lacey \& Sherman, 1991; Faulkes et al., 1991), naked mole-rats exhibit perhaps the most extreme example of socially-induced suppression of reproduction so far discovered in mammals. Within both captive and wild colonies, reproduction is restricted to a single breeding female, the 'queen', while in the remaining non-breeding females ovulation is blocked (Faulkes et al., 1990a), possibly as a result of inadequate plasma LH concentrations arising from impaired hypothalamic GnRH secretion (Faulkes et al., 1990b). Behavioural observations have also shown that reproduction is restricted to 1, 2 or sometimes 3 
male naked mole-rats (Jarvis, 1981; Brett, 1986; Lacey \& Sherman, 1991; Faulkes et al., 1991). Behaviourally, differences between breeding and non-breeding males are clear-cut in that only the breeding males are solicited by, and mate with, the queen (Jarvis, 1991). However, anatomical differences in the reproductive tract of males are apparently less distinct, because Jarvis (1991) found that, out of 84 wild-caught males, $76 \%$ had spermatozoa in their vas deferens. This suggests that most non-breeding male naked mole-rats may potentially be capable of fertilizing a female, should they mate. This is different from non-breeding female naked mole-rats, in which the development of mature gametes does not appear to occur because ovulation is blocked (Faulkes, 1990; Faulkes et al., 1990a).

The following study was undertaken to confirm that spermatogenesis was occurring in nonbreeding males, by histological examination, and to examine whether differences in breeding status in males were reflected by differences in concentrations of reproductive hormones. As reduced pituitary LH secretion was implicated in reproductive suppression in female naked mole-rats (Faulkes et al., 1990a, b), plasma LH concentrations and LH response to exogenous GnRH administration were investigated in breeding and non-breeding males, together with determinations of urinary testosterone values as a measure of testicular function.

\section{Materials and Methods}

\section{Animals and sampling}

Animals. Captive colonies of naked mole-rats were maintained at the Institute of Zoology, London, and at the University of Cape Town, South Africa, using artificial burrow systems, the details of which have been described previously (e.g. Faulkes et al., 1990a, b). The total tunnel length of these artificial burrows varied from 2 to $15 \mathrm{~m}$, according to the number of animals in the colony, which ranged from pairs up to 72 individuals. In captivity, animals were numbered and identified by a system of toe clipping and tattoos. Breeding males were distinguished from nonbreeders by observations of mating. Altogether 61 males from 24 captive colonies were used in this study.

Naked mole-rats from wild colonies were captured near Mtito Andei, Kenya, approximately $230 \mathrm{~km}$ south-east of Nairobi, as described by Faulkes et al. (1990c). A total of 52 males from 4 wild colonies were used in this study.

Collection and fixation of reproductive tract tissue. From captive colony males, reproductive tracts were either removed at post mortem, no more than $12 \mathrm{~h}$ after the death of the animal, or removed within $30 \mathrm{~min}$ of euthanasia. The reproductive tract was cut just below the junction of the left and right vas deferens, and the abdominal testes, together with the attached vasa deferentia were then removed. Tissue was fixed by immersion in $10 \%$ formal saline. Tissue samples collected from colonies in the wild were fixed by immersion in $4 \%$ paraformaldehyde in saline within $15 \mathrm{~min}$ of killing the animal.

All samples were fixed for 7 days to 24 months (captive and wild-caught animals) before measurement of testicular mass (testes plus epididymis and vasa deferentia, as detailed above) and histology. Because an accurate balance was not available in the field, it was not possible to weigh the reproductive tracts and gonads of wild-caught animals before fixation. Therefore, all measurements of testicular mass were made on fixed material, and the results are based on the assumption that any size changes in the tissues examined, resulting from the process of fixation, were constant across all the samples.

Urine sampling. Urine was chosen for routine testosterone determination in captive colonies in preference to blood because it is a non-invasive technique and disturbance to the animals was minimized. Urine is also widely used as a medium for hormonal analysis in other species (e.g. Lasley, 1985; Hodges, 1986), and the female naked mole-rat (Faulkes et al., 1990a), and the analytical methods have been well validated.

Urine sampling involved the removal of all the shavings from the toilet chamber in each colony and wiping the chamber clean with tissue paper. Immediately after each urination, the sample was collected in a glass pipette. After collection of each sample, the toilet chamber was wiped clean with tissue paper. Samples were placed in a freezer within $1 \mathrm{~h}$ of collection, and stored at $-20^{\circ} \mathrm{C}$ until hormone determination. Sampling was carried out between 08:00 and $18: 00 \mathrm{~h}$.

Blood sampling. Animals were hand-held, the tip of the tail was cut with a sterile scalpel blade and blood (approximately $200 \mu \mathrm{l}$ ) was collected by capillary action using heparinized micro-haematocrit tubes. Blood samples were collected within 2-4 min of animal capture from the captive colonies, and subsequent blood samples were collected from the same wound, after removing the clot by washing with sterile saline. The total amount of blood taken from each animal after serial sampling did not exceed $800 \mu$ l, and after the last blood sample had been collected, the wound was treated with antibiotic powder (Aureomycin), and the animal returned to its colony. After collection the samples were stored on ice for a maximum of $2 \mathrm{~h}$ before being centrifuged for $5 \mathrm{~min}$ at $500 \mathrm{~g}$, and the plasma was stored at $-20^{\circ} \mathrm{C}$ before $\mathrm{LH}$ determination. 


\section{Hormone determinations}

Radioimmunoassay of testosterone. Before testosterone assay all urine samples were subjected to a determination of urinary creatinine as described by Bonney et al. (1982). All urinary testosterone concentrations were expressed as mass per $\mathrm{mg}$ creatinine $(\mathrm{mg} / \mathrm{Cr})$ to correct for dilution of urine.

Chromatographic separation of testosterone from the samples were required before radioimmunoassay, because there was a significant difference between urinary testosterone concentrations in samples assayed with and without chromatography $(32.4 \pm 12.3$ and $108.8 \pm 37 \cdot 1$ respectively; paired $t$ test, $t=2.95$, d.f. $=8, P<0.02)$.

The method for separating testosterone using Celite column chromatography has been previously described by Hodges et al. (1981) for primates, and by Faulkes (1990) for naked mole-rats. Briefly, this involved washing columns of Celite:ethylene glycol $(2: 1 \mathrm{w} / \mathrm{v})$ with $8.0 \mathrm{ml}$ iso-octane, followed by addition of a further 3.5 and $5.0 \mathrm{ml}$ iso-octane which eluted progesterone and dihydrotestosterone from the column, respectively. These fractions were discarded. After rinsing the column with $2.0 \mathrm{ml}$ iso-octane, the testosterone fraction was eluted and collected after addition of $5.0 \mathrm{ml}$ cyclohexane:benzene $(95: 5, \mathrm{v} / \mathrm{v})$. After evaporation of solvent, the samples were reconstituted in $1.0 \mathrm{ml}$ buffer and subjected to testosterone radioimmunoassay as described below.

Testosterone concentrations were determined in diethyl ether-extracted urine $(50-100 \mu \mathrm{l})$ by radioimmunoassay following Celite chromatography, using sheep anti-testosterone antibody no. 505 (MRC Reproductive Physiology Unit, Edinburgh, UK; see Hodges et al., 1987).

The sensitivity of the assay (determined as $90 \%$ binding) was $2.0 \mathrm{pg} /$ tube. At an average dilution of urine this was equivalent to $<1.0 \mathrm{ng} / \mathrm{mg} \mathrm{Cr}$. Inter-assay precision, expressed as the coefficient of variation for repeated determinations of a quality control $(2 \cdot 22 \mathrm{ng} / \mathrm{mg} \mathrm{Cr})$, was $15 \cdot 1 \%(n=4)$ for quality controls subjected to column chromatography and $16.9 \%(n=4)$ for quality controls extracted only. Intra-assay variation was $7.5 \%(n=7)$.

The assay was validated for use in the naked mole-rat by tests of accuracy and parallelism. Accuracy was assessed by addition of urine to the reference preparation. The mean \pm s.e.m. recovery of unlabelled testosterone added to a naked mole-rat urine pool was $92.6 \pm 10.0 \%(n=4)$ over the standard curve range of $2 \cdot 5-160 \mathrm{pg} /$ tube. Parallelism was demonstrated by an absence of a significant interaction between preparation (testosterone standard $v s$ urine containing high levels of testosterone) and dilution, when using a two-way ANOVA repeated-measures design $(\mathrm{F}(5,10)=0.78 ; P>0.58)$ (Sokal \& Rohlf, 1981).

Luteinizing hormone bioassay. LH was measured using an in-vitro bioassay based on the production of testosterone by dispersed mouse Leydig cells (Van Damme et al., 1974). Details of the method have been described previously (Harlow et al., 1984; Hodges et al., 1987; Abbott et al., 1988). Plasma samples were assayed in duplicate at two dilutions of 1:10 and 1:20, or 1:20 and 1:40, as a routine check for parallelism, and compared with a rat LH standard (the rLH antigen preparation: $\mathrm{rLH}-\mathrm{I}-7$ ) over the range $2-0.0625 \mathrm{mi} . \mathrm{u} . / \mathrm{ml}$. The testosterone produced was measured the radioimmunoassay described by Hodges et al. (1987).

To validate the LH bioassay for the naked mole-rat, dilutions of plasma samples taken before or after GnRH treatment, and of a pituitary homogenate containing high concentrations of $\mathrm{LH}$, were shown to be parallel to, and not significantly different from, the reference preparation (see Faulkes et al., 1990b, for further details).

The sensitivity of the assay (determined at $90 \%$ binding) was 0.1 mi.u. per tube. Intra- and inter-assay precision for the whole assay, expressed as the mean coefficients of variation for repeated determinations of an LH quality control $(1.53 \mathrm{mi} . \mathrm{u} . / \mathrm{ml})$, were $10 \%(n=15)$ and $16 \%(n=9)$, respectively.

\section{Experimental procedures}

Measurement of reproductive tract masses. Testes, including epididymides and vasa deferentia, from captive breeding ( 4 males from 4 colonies), captive non-breeding ( 6 males from 3 colonies), and wild-caught ( 52 males from 4 colonies) male naked mole-rats were individually weighed. Although the reproductive status of the wild-caught males was not known, they were assumed to be non-breeders because the mass of their testes resembled those of captive nonbreeders, and because in both wild and captive colonies, only 1-3 males are of breeding status (Jarvis, 1981; Brett, 1986; Lacey \& Sherman, 1991).

Histology. Testes from captive breeding $(n=4)$, captive non-breeding $(n=6)$ and wild-caught males $(n=3$, assumed to be non-breeders due to the low body mass of the animals, and the small testes masses which were comparable to those of other non-breeding males), were examined. Sections $0.5-0.8 \mu \mathrm{m}$ thick were cut from tissue embedded in paraffin wax, and stained for light microscopy with haematoxylin-eosin. Full details of the method are described by Faulkes (1990). Photomicrography was carried out with a Zeiss Ultraphot 2 photomicroscope, using $35 \mathrm{~mm}$ Kodak Pan-F black and white film.

Urinary testosterone in breeding and non-breeding males. To investigate differences in urinary testosterone concentrations between breeding and non-breeding males as a possible reflection of differences in testicular function, 142 samples were collected from 9 breeding males from 9 colonies, and 72 samples were collected from 12 non-breeding males from 8 colonies.

Plasma $\mathbf{L H}$ in breeding and non-breeding males. To investigate possible differences in pituitary function in breeding and non-breeding males, 27 plasma samples were collected from 14 breeding males from 13 colonies, while 37 plasma samples were collected from 24 non-breeding males from 8 colonies. Bioactive LH concentrations in these samples were then measured. 
$\boldsymbol{G n R H}$ administration. To investigate possible differential LH responses of the pituitary to stimulation by GnRH, the effects of administration of exogenous $\mathrm{GnRH}$ were investigated in breeding $(\mathrm{N}=17)$ and non-breeding $(\mathrm{N}=30)$ male naked mole-rats. Three solutions of $0.5,2.5$ and $5.0 \mu \mathrm{g} \mathrm{GnRH}$ (NIDDKD) per ml sterile saline were divided into $1-\mathrm{ml}$ samples and stored at $-20^{\circ} \mathrm{C}$ until required. In all experiments the $\mathrm{GnRH}$ was administered subcutaneously as a $200 \mu \mathrm{l}$ injection, giving doses of $0 \cdot 1,0.5$ and $1.0 \mu \mathrm{g} \mathrm{GnRH} / 200 \mu \mathrm{l}$ saline. In Exp. 1, blood samples were taken immediately before, then $20 \mathrm{~min}$ after, a single subcutaneous injection of $0.1,0.5$ or $1.0 \mu \mathrm{g} \mathrm{GnRH}$ in $200 \mu \mathrm{l}$ saline (4-6 animals), or of saline alone $(\mathrm{N}=3)$, in breeding and non-breeding male naked mole-rats. In Exp. 2, blood samples were taken from non-breeding males before, then $20 \mathrm{~min}$ after, 4 and 8 subcutaneous injections of $0.1(\mathrm{~N}=5), 0.5$ $(\mathrm{N}=6)$ or $1.0 \mu \mathrm{g}(\mathrm{N}=6) \mathrm{GnRH}$ in $200 \mu \mathrm{l}$ saline, or of saline alone $(\mathrm{N}=3)$, administered at 1 -h intervals.

Statistical analysis. Reproductive tract masses, urinary testosterone and basal plasma LH data were analysed using Student's $t$ test, while GnRH challenge data were subjected to analysis of variance for repeated measures following log transformation. Plasma LH concentrations after single GnRH administration were analysed by twoway analysis of variance for repeated measures. Due to a significant interaction at the $0.5 \mu \mathrm{g}$ dose, results from this dose were subjected to one-way analysis of variance. Plasma LH concentrations after multiple GnRH administration were analysed by one-way analysis of variance for repeated measures. Log transformation of plasma LH concentrations was carried out as a standard procedure, to increase the linearity of the data and to reduce the heterogeneity of variance (Sokal \& Rohlf, 1981). Results quoted in the text are means \pm s.e.m. for the non-transformed data, while the figures reflect the data as the antilog of the means transformed for statistical analysis, together with their $95 \%$ confidence limits. Comparisons of individual transformed means were made post hoc using Duncan's multiple-range test with a level of significance of $P=0.05$ (Helwig \& Council, 1979).

\section{Results}

\section{Reproductive tract masses}

The absolute and relative to body mass testicular masses (testes, epididymides and vasa deferentia) for captive breeding and non-breeding males, and wild-caught males of assumed nonbreeder status are given in Table 1.

Table 1. Mean \pm s.e.m. testicular mass in captive breeding, nonbreeding and wild caught male naked mole-rats

\begin{tabular}{lccc}
\hline Male status & $\begin{array}{c}\text { No. of } \\
\text { males }\end{array}$ & $\begin{array}{c}\text { Total } \\
\text { testicular mass } \\
(\mathrm{mg})\end{array}$ & $\begin{array}{c}\text { Total } \\
\text { testicular mass/ } \\
\text { body mass } \\
(\mathrm{mg} / \mathrm{g})\end{array}$ \\
\hline Captive breeder & 4 & $79 \cdot 0 \pm 14 \cdot 7^{*}$ & $2 \cdot 0 \pm 0 \cdot 2 \dagger$ \\
Captive non-breeder & 6 & $34 \cdot 0 \pm 2 \cdot 9$ & $1 \cdot 2 \pm 0 \cdot 1$ \\
Wild caught & 52 & $33 \cdot 9 \pm 2 \cdot 2$ & $1 \cdot 5 \pm 0 \cdot 3$ \\
\hline
\end{tabular}

* $P<0.01$ compared with values for the other two groups.

$\dagger P<0.01$ compared with values for captive non-breeders.

Relative to body mass, captive breeding males had a significantly higher total testicular mass $(P<0.01, t=3 \cdot 70$, d.f. $=8)$, than did captive non-breeding males. The absolute testicular masses were also significantly different between captive breeding and captive non-breeding males $(P<0 \cdot 01, t=3 \cdot 59$, d.f. $=8)$, and between captive breeding and wild-caught males $(P<0.01, t=$ 3.03 , d.f. $=54)$. The mass of the reproductive tracts of wild-caught males resemble those of captive non-breeders, and not of captive breeders. It was therefore likely that the reproductive tracts of the wild-caught males were taken from non-breeders.

\section{Histology}

Representative sections from the testis and epididymis of one breeding and one non-breeding male are illustrated in Fig. 1. There was evidence of spermatogenesis in all the breeding and non- 
breeding males examined in this study. Various numbers of spermatozoa were present in the seminiferous tubules of all the animals, e.g. Figs 1 (a) and (b), indicating active spermatogenesis. In addition, large numbers of spermatozoa were evident in the lumen of the epididymis of nonbreeding males (Fig. 1d). This indicates that, as well as undergoing spermatogenesis, these nonbreeding males were also apparently producing mature spermatozoa. A striking feature of the testes of breeding and non-breeding male naked mole-rats was the presence of large amounts of interstitial tissue, when compared with laboratory rodents such as mice and rats (e.g. Fawcett et al., 1973). Although no quantitative measurements were made, visual examination of the histological sections suggested that, in breeding males, there were greater numbers of interstitial cells than in non-breeders. This may have contributed, at least in part, to the larger testicular mass of breeding males.

\section{Urinary testosterone}

Urinary testosterone concentrations showed high individual variation (Table 2), ranging from 0.3 to $42.4 \mathrm{ng} / \mathrm{mg} \mathrm{Cr}$ in non-breeding male naked mole-rats, and from 1.0 to $176.4 \mathrm{ng} / \mathrm{mg} \mathrm{Cr}$ in breeding males.

Despite this individual variation, the grand means of these individual means revealed differences in the urinary testosterone concentrations between breeding and non-breeding males, with breeders having significantly higher values $(23.8 \pm 2.3$ vs $5.2 \pm 1.4 \mathrm{ng} / \mathrm{mg}$ Cr respectively; $P<0.001 ; t=6.96$, d.f. $=20$ ).

The overall mean value of urinary testosterone in the 9 breeding males was $24 \mathrm{ng} / \mathrm{mg} \mathrm{Cr}$. Of the 12 non-breeders listed in Table 2, only 4 of these males had urinary testosterone concentrations that were comparable to or exceeded $24 \mathrm{ng} / \mathrm{mg} \mathrm{Cr}$. However, these instances of high urinary testosterone in non-breeding males occurred relatively infrequently. Only $8 \%$ of values from non-breeders exceeded $24 \mathrm{ng} / \mathrm{mg} \mathrm{Cr}$ (the mean value for breeding males), and the highest value obtained was $42.4 \mathrm{ng} / \mathrm{mg} \mathrm{Cr}$. In breeding males, $30 \%$ of samples had urinary testosterone concentrations that exceeded $24 \mathrm{ng} / \mathrm{mg} \mathrm{Cr}$, with the highest value reaching $176 \mathrm{ng} / \mathrm{mg} \mathrm{Cr}$. These results show that overlap between the highest values of urinary testosterone in non-breeding males and the mean value for breeding males does occur in some individuals, but that most of the time breeding males maintained higher urinary testosterone concentrations which were mostly greatly in excess of those found in non-breeding males (Table 2).

\section{Plasma LH}

The differences in urinary testosterone concentrations between breeding and non-breeding male naked mole-rats were reflected in the circulating concentrations of LH. Breeding males had significantly higher plasma $\mathrm{LH}$ concentrations compared with non-breeders $(10.7 \pm 1.7$ and $5.0 \pm 0.8 \mathrm{mi} . \mathrm{u} . / \mathrm{ml}$ respectively; $P<0.01, t=3.05$, d.f. $=63$ ).

\section{GnRH treatment}

Experiment 1: $L H$ responses to a single injection of $G n R H$. Administration of $\mathrm{GnRH}$ produced significant increases in circulating $\mathrm{LH}$ concentrations at all doses in breeding and non-breeding males (Fig. 2, $\mathrm{F}(3,31)=26.21 ; P<0.001$ ). There was no response to the saline control injections in breeding or non-breeding male naked mole-rats $(\mathrm{F}(1,4)=1.83 ; P>0 \cdot 25)$.

This experiment revealed differences in $\mathrm{LH}$ responses to $\mathrm{GnRH}$ in breeding males compared with non-breeding males. While there was no significant difference in LH response at any of the three doses of GnRH in breeding males $(P>0.05)$, non-breeding males showed a dose-response which gave rise to lower plasma $\mathrm{LH}$ concentrations $20 \mathrm{~min}$ after a single injection of 0.1 or $0.5 \mu \mathrm{g}$ GnRH, compared with breeding males (Fig. 2), suggesting that the pituitaries of non-breeding males were less sensitive to the lower doses of GnRH. 
(a)

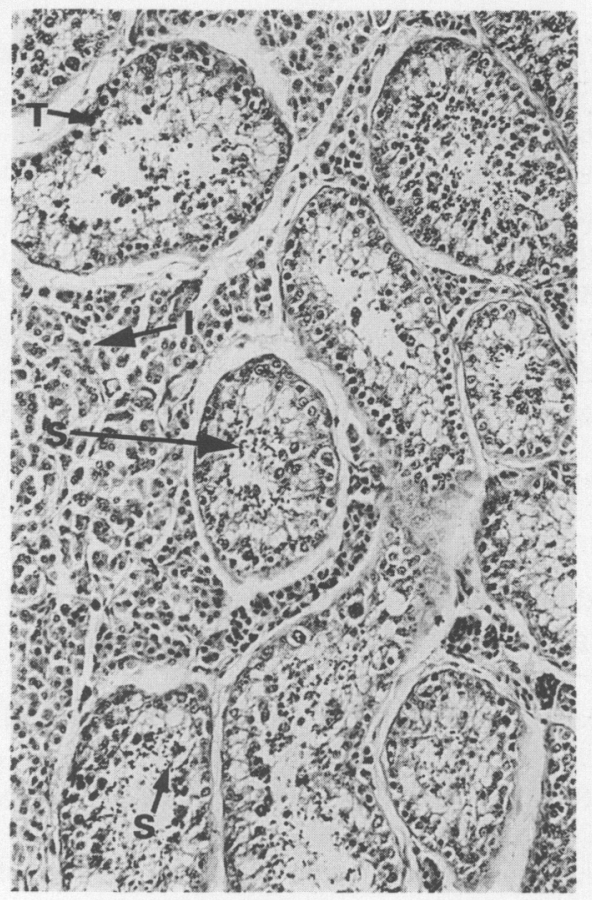

(b)

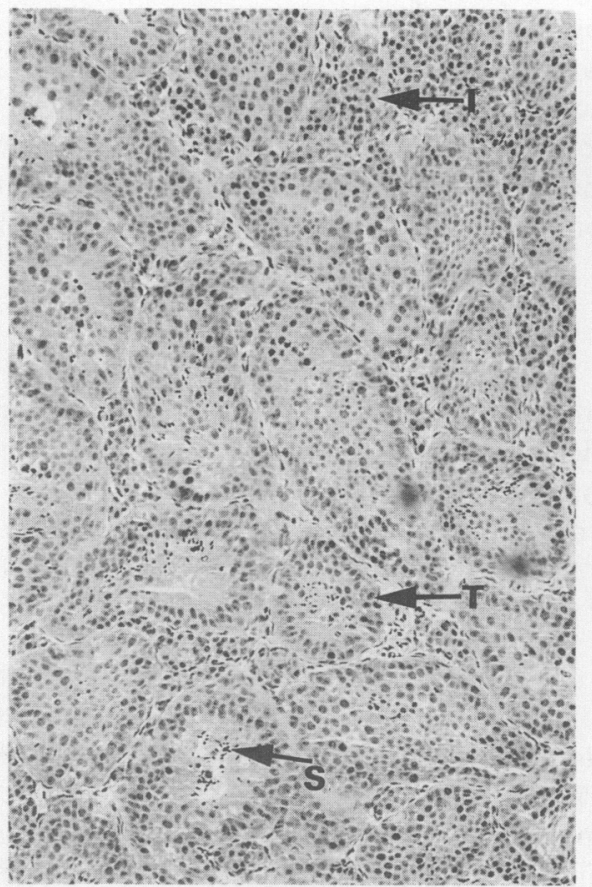

(c)

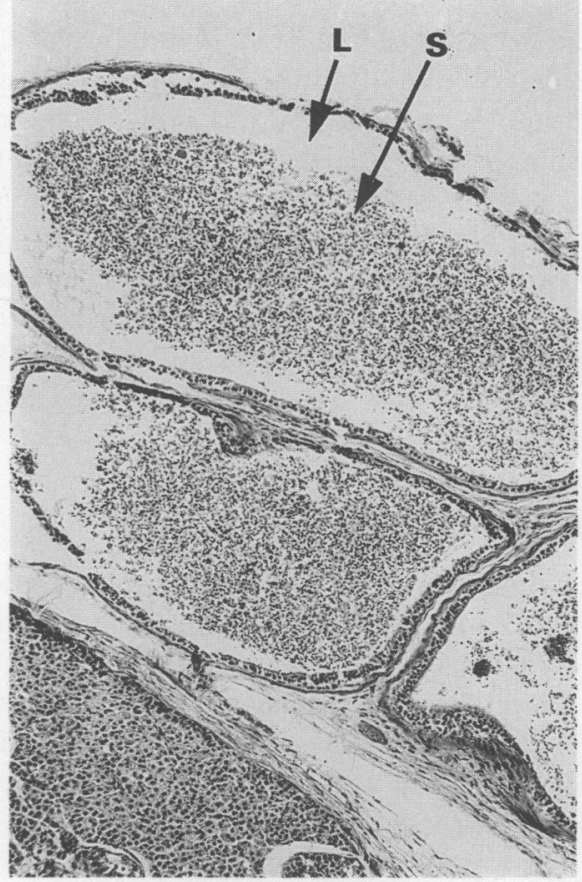

(d)

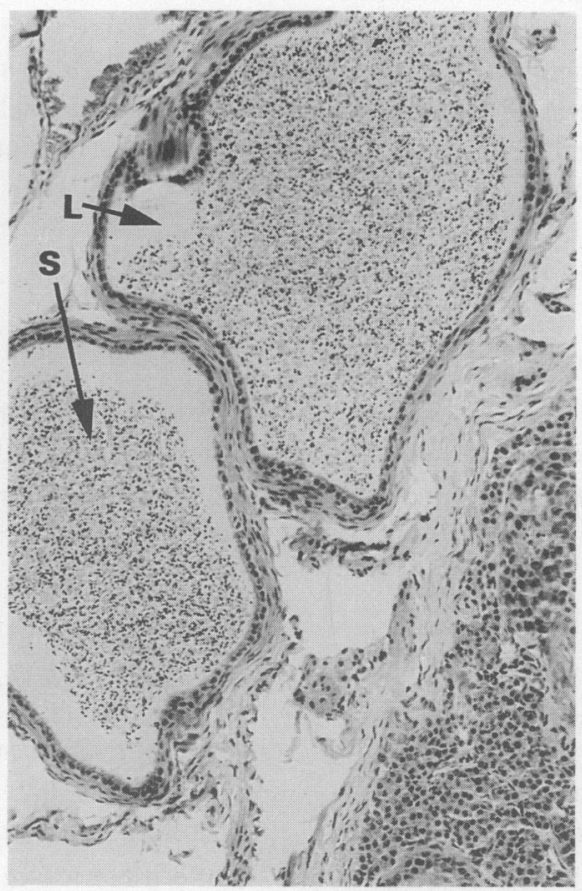

Fig. 1. Representative transverse section through the testes (a, b) and epididymides (c, d) of a breeding ( $a, c)$ and a non-breeding (b, d) naked mole-rat. I=interstitial (Leydig) cells, $\mathrm{S}=$ spermatozoa; $\mathrm{T}=$ seminiferous tubule; $\mathrm{L}=$ lumen of epididymis. $\mathrm{a}, \times 62.5 ; \mathrm{b}, \times 100$; c, $\times 100 ; \mathrm{d}, \times 100$. 
Table 2. Mean and range of urinary testosterone values (ng/mg $\mathrm{Cr}$ ) taken from 9 breeding and 12 non-breeding naked mole-rats

\begin{tabular}{|c|c|c|c|c|c|c|c|}
\hline \multicolumn{4}{|c|}{ Non-breeding males } & \multicolumn{4}{|c|}{ Breeding males } \\
\hline Animal & Mean & Range & $\begin{array}{l}\text { No. of } \\
\text { samples }\end{array}$ & Animal & Mean & Range & $\begin{array}{c}\text { No. of } \\
\text { samples }\end{array}$ \\
\hline B9* & 6.4 & $1.0-29.2$ & 9 & K9 & $18 \cdot 7$ & $1 \cdot 0-112 \cdot 3$ & 26 \\
\hline B16 & $4 \cdot 8$ & $1 \cdot 0-36 \cdot 0$ & 20 & $\mathrm{~J} 16$ & 23.9 & $1.0-114.0$ & 28 \\
\hline B22 & $3 \cdot 6$ & $1 \cdot 0-5 \cdot 4$ & 3 & D22 & $24 \cdot 8$ & $1.0-118.0$ & 14 \\
\hline D88 & $6 \cdot 4$ & $1 \cdot 0-11 \cdot 3$ & 7 & H88 & $32 \cdot 7$ & $1.0-176.4$ & 13 \\
\hline Al0 & 1.8 & $1 \cdot 2-2 \cdot 3$ & 2 & N98 & $30 \cdot 1$ & $3.6-154.7$ & 18 \\
\hline A14 & 1.4 & - & 1 & O8 & $29 \cdot 6$ & $1 \cdot 0-71 \cdot 5$ & 10 \\
\hline A27 & 0.7 & $0 \cdot 3-1 \cdot 0$ & 2 & P3 & $17 \cdot 6$ & $1 \cdot 7-42 \cdot 6$ & 9 \\
\hline B27 & 1.8 & $1 \cdot 0-2 \cdot 6$ & 2 & Q1 & $24 \cdot 7$ & $1.0-95.5$ & 19 \\
\hline 2208 & $17 \cdot 7$ & $3 \cdot 4-42 \cdot 4$ & 5 & $\mathrm{R} 40$ & $11 \cdot 7$ & $2 \cdot 7-24 \cdot 1$ & 5 \\
\hline 2203 & $10 \cdot 2$ & $3 \cdot 4-26 \cdot 4$ & 12 & & & & \\
\hline 2201 & $2 \cdot 8$ & $1 \cdot 0-7 \cdot 0$ & 7 & & & & \\
\hline 2240 & $4 \cdot 5$ & $1 \cdot 0-8.8$ & 3 & & & & \\
\hline \multicolumn{2}{|c|}{ Grand mean \pm s.e.m. } & $5 \cdot 2-1 \cdot 4$ & & & & $23 \cdot 8-2 \cdot 3$ & \\
\hline
\end{tabular}

*The letter prefix to the animal number identifies the colony to which the animal belonged.

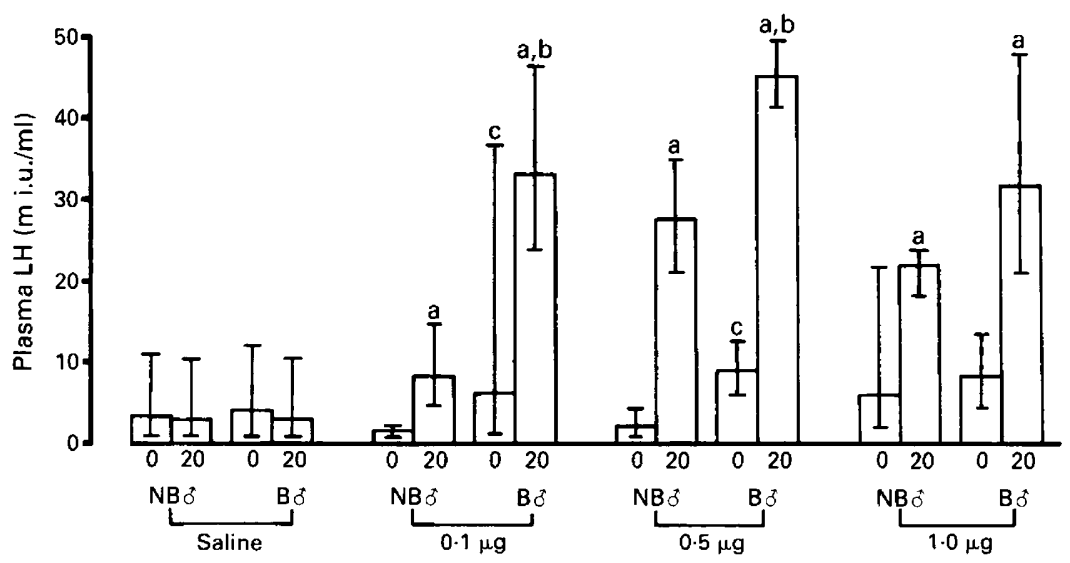

Fig. 2. Concentrations of plasma LH (antilog of the transformed mean $\pm 95 \%$ confidence limits) in breeding $\left(\mathrm{B}^{*}\right)$ and non-breeding $\left(\mathrm{NB}^{*}\right)$ male naked mole-rats before $(0)$, and $20 \mathrm{~min}$ after (20), a single s.c. injection of $0.1,0.5$ or $1.0 \mu \mathrm{g} \mathrm{GnRH}$, or saline. a, $P<0.05$ vs 0 time; b, $P<0.05$ vs non-breeding males at $20 \mathrm{~min}$; c, $P<0.05$ vs non-breeding males at 0 time (Duncan's multiple range test following ANOVA for repeated measures).

Administration of $1.0 \mu \mathrm{g} \mathrm{GnRH}$ produced an increase in plasma LH in breeders that was not significantly different from that of non-breeding males $(8.3 \pm 1.7$ to $32.8 \pm 5.0 \mathrm{mi} . \mathrm{u} . / \mathrm{ml}, \mathrm{N}=5$, and $8.0 \pm 2.0$ to $21.6 \pm 1.3 \mathrm{mi} . \mathrm{u} . / \mathrm{ml}, \mathrm{N}=5$ respectively; $\mathrm{F}(1,8)=1.53, P>0.25)$. With $0.5 \mu \mathrm{g}$ GnRH, maximum LH responses were obtained in breeding $(\mathrm{N}=5)$ and non-breeding $(\mathrm{N}=5)$ males, although at this dose breeding males produced significantly greater plasma concentrations of $\mathrm{LH} 20 \mathrm{~min}$ after injection $(8.9 \pm 1.2$ to $45.1 \pm 1.4 \mathrm{mi} . \mathrm{u} . / \mathrm{ml}, \mathrm{N}=5$, and $2.1 \pm 0.7$ to $27.6 \pm 2.6 \mathrm{mi} . \mathrm{u} . / \mathrm{ml}, \mathrm{N}=5$, respectively; $\mathrm{F}(1,8)=25.95, P<0.001)$. At the lowest dose of $0.1 \mu \mathrm{g}$ GnRH, the difference in $\mathrm{LH}$ response between breeding and non-breeding males was greatest 
$(\mathrm{F}(1,7)=17 \cdot 14 ; P<0 \cdot 005)$. Non-breeders $(\mathrm{N}=5)$ produced only a small increase in plasma $\mathrm{LH}$ concentrations from $1.5 \pm 0.2$ to $8.9 \pm 0.5 \mathrm{mi}$.u. $/ \mathrm{ml}$, compared with breeding males $(\mathrm{N}=4)$, whose plasma $\mathrm{LH}$ rose from $10.0 \pm 6.4$ to $33.7 \pm 3.7 \mathrm{mi} . \mathrm{u} . / \mathrm{ml}$.

Basal concentrations of plasma LH ( 0 time values in this study) were significantly lower in nonbreeding males compared with breeding males in the 0.1 and $0.5 \mu \mathrm{g}$ treatment groups $(P<0.05)$, reflecting the results described in the previous section. There was no difference in basal plasma $\mathrm{LH}$ concentrations between breeding and non-breeding males in the $1.0 \mu \mathrm{g}$ treatment group, probably because of the relatively small group sizes and the relatively high intra-group variability in concentrations of plasma LH (Fig. 2).

Experiment 2: multiple injections of $\mathbf{G n R H}$. GnRH produced a significant increase in concentrations of plasma $\mathrm{LH}$ in non-breeding males after $4(2.8 \pm 0.7$ to $10.6 \pm 1.6 \mathrm{mi}$.u. $/ \mathrm{ml}, \mathrm{N}=5)$ or 8 $(2.8 \pm 0.7$ to $11.1 \pm 2.4 \mathrm{mi} . \mathrm{u} . / \mathrm{ml}, \mathrm{N}=5) 0.1 \mu \mathrm{g}$ injections of $\mathrm{GnRH}$, comparable with the basal concentration of LH ( 0 time) in breeding males $(10.3 \pm 6.3 \mathrm{mi} . \mathrm{u} . / \mathrm{ml}, \mathrm{N}=5$; Fig. 3a). At this dose, repeated $\mathrm{GnRH}$ injections to non-breeding males did not reverse the apparent lack of pituitary sensitivity to exogenous GnRH. Plasma LH concentrations after a single injection of $0 \cdot 1 \mu \mathrm{g} \mathrm{GnRH}$ in breeding males were significantly greater than $\mathrm{LH}$ responses to $\mathrm{GnRH}$ in non-breeding males given 4 or $80.1 \mu \mathrm{g}$ injections $(\mathrm{F}(7,24)=17.86 ; P<0.001 ;$ Fig. 3a). There was no response to repeated saline injections.

Figure 3(b) summarizes the results obtained after administering multiple doses of $0.5 \mu \mathrm{g} \mathrm{GnRH}$ to non-breeding males $(\mathrm{N}=5)$. At this dose, plasma $\mathrm{LH}$ concentrations increased from $3.9 \pm 1 \cdot 5$ to $29.5 \pm 2.8 \mathrm{mi} . \mathrm{u} . / \mathrm{ml}$ after 4 injections, and to $18.2 \pm 2.3 \mathrm{mi} . \mathrm{u} . / \mathrm{ml} 20 \mathrm{~min}$ after 8 consecutive hourly injections. Plasma concentrations of LH in non-breeding males after 4 injections were not significantly different from those of breeding males given a single $0.5 \mu \mathrm{g}$ injection (Fig. $3 \mathrm{~b}$ ). At this dose, therefore, 4 repeated injections of $\mathrm{GnRH}$ were sufficient to reverse the lack of sensitivity to single injections of exogenous $\mathrm{GnRH}$ at this dose in non-breeding males.

Although there was no statistical difference in LH response between breeding and non-breeding males given a single injection of the highest GnRH dose of $1.0 \mu \mathrm{g}$, the effects of multiple GnRH injections as this dose were also investigated in non-breeders (Fig. 3c). The LH response in nonbreeding males following multiple injections of $\mathrm{GnRH}$ was greatest at this dose: plasma LH concentrations increased from $3.3 \pm 1.1$ to $40.3 \pm 7.8 \mathrm{mi} . \mathrm{u} . / \mathrm{ml}$ after 4 injections and decreased to $27 \cdot 0 \pm 5.0 \mathrm{mi} . \mathrm{u} . / \mathrm{ml}$ after 8 injections. Both values were comparable to those of breeding males after a single injection of $1.0 \mu \mathrm{g} \mathrm{GnRH} \mathrm{(32.8} \pm 5 \cdot 1 \mathrm{mi} . \mathrm{u} . / \mathrm{ml}$; Fig. $3 \mathrm{c})$.

\section{Discussion}

While breeding naked mole-rat males had larger testes, both in terms of absolute size and relative to their body mass, microscopic examination revealed the presence of spermatozoa in the seminiferous tubules and epididymides of breeding and non-breeding males, suggesting that active spermatogenesis was occurring in these animals, and confirming the observations of Jarvis (1991). Breeding and non-breeding naked mole-rats exhibited a sparse distribution of seminiferous tubules, and the presence of large quantities of interstitial cells, as reported by Fawcett et al. (1973) and Jarvis (1991). Histological examination suggested that the greater testis size of breeding males may have been due to the presence of greater numbers of interstitial cells than in non-breeders. The functional significance of this remains unknown, but large accumulations of testicular interstitial tissue do not appear to be a characteristic of hystricomorph rodents per se, because it was not observed in chinchilla, Chinchilla laniger, or agouti, Dasyprocta aguti (Weir, 1967). Fawcett et al. (1973) estimated that interstitial cells made up approximately $60 \%$ of the testicular mass in naked mole-rats, although the breeding status of the animals which were investigated was not noted. This was markedly different from the guinea-pig, in which interstitial cells were found to represent only about $2 \%$ of the volume of the testis (Fawcett et al., 1973). 

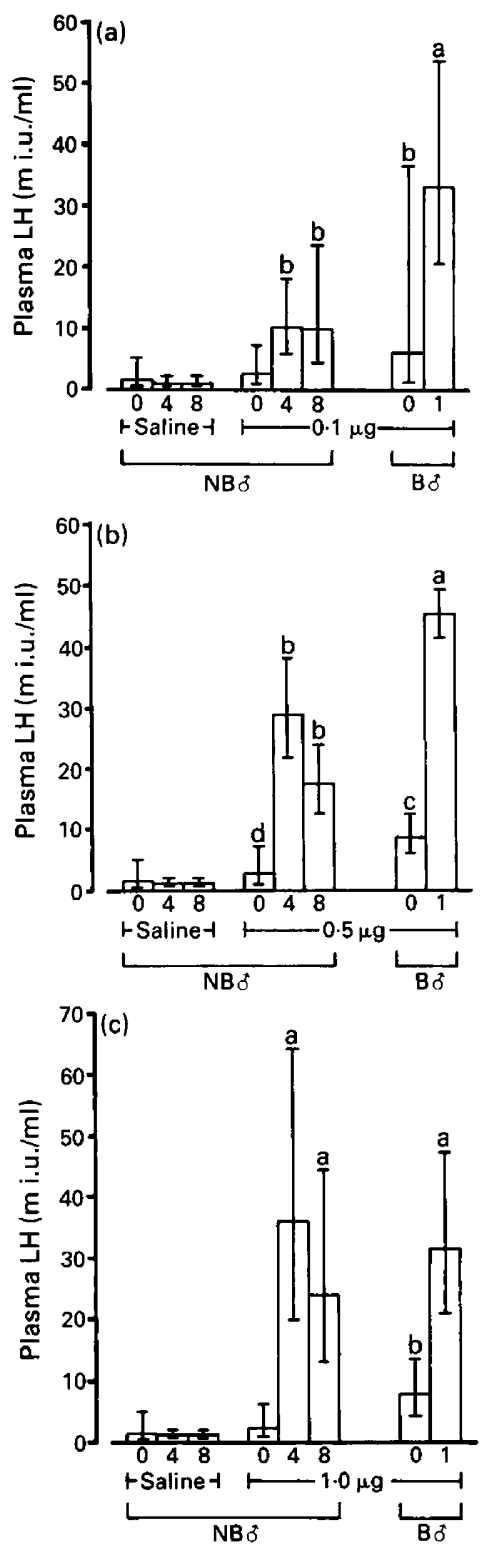

Fig. 3. Concentrations of plasma $\mathrm{LH}$ (antilog of the transformed mean $\pm 95 \%$ confidence limits) in breeding (B $\left.\delta^{*}\right)$ and non-breeding $\left(\mathrm{NB}^{*}\right)$ male naked mole-rats before $(0)$, and 20 min after, a single s.c. injection (1), or $20 \mathrm{~min}$ after the last of 4 or 8 s.c. injections of GnRH given at hourly intervals, or an equivalent saline control. (a) $0.1 \mu \mathrm{g} \mathrm{GnRH} \mathrm{dose:} \mathrm{a,} P<0.05$ vs breeding males at time 0 and all non-breeding male values; $b, P<0.05 v s$ non-breeding males at 0 time and saline controls. (b) $0.5 \mu \mathrm{g}$ GnRH dose: a, $P<0.05$ vs 0 time values (B ${ }^{\wedge}$ and $\mathrm{NB}^{\top}$ ), saline

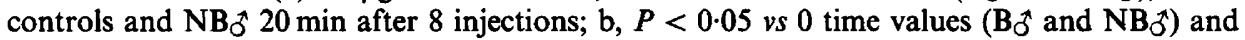
saline controls; c, $P<0.05$ vs NB 0 time values and saline controls; $\mathrm{d}=P<0.05$ vs saline controls. (c) $1.0 \mu \mathrm{g}$ GnRH dose: a, $P<0.05$ vs 0 time values (B ${ }^{\dagger}$ and $\mathrm{NB}_{\delta}{ }^{\gamma}$ ), saline controls; $\mathrm{b}$, $P<0.05$ vs NB $\sigma^{*} 0$ time values and saline controls. (Duncan's multiple-range test following 1-way ANOVA for repeated measures.) 
Despite the fact that spermatogenesis was occurring in all the males examined, the endocrine results show that, as with female naked mole-rats, there were clear physiological differences between breeding and non-breeding males. Breeding males had significantly higher basal concentrations of plasma $\mathrm{LH}$, and greater $\mathrm{LH}$ responses to single injections of $\mathrm{GnRH}$ at lower doses $(0.1$ and $0.5 \mu \mathrm{g})$, compared with non-breeding males. The lower concentrations of plasma $\mathrm{LH}$ in non-breeding males were reflected in lower concentrations of urinary testosterone in these individuals.

While basal concentrations of plasma LH in non-breeding males were less than in breeding males, they were, however, higher than those measured in non-breeding females $(5.0 \pm 0.8$ and $1.6 \pm 0.1 \mathrm{mi} . \mathrm{u} . / \mathrm{ml}$ respectively; Faulkes et al., 1990b). It is not known whether these differences in plasma $\mathrm{LH}$ concentrations are due to changes in $\mathrm{LH}$ pulse frequency or amplitude of $\mathrm{LH}$ secretion from the pituitary. While a physiological suppression mechanism appears to be in operation in non-breeding male naked mole-rats, the hypothalamic-gonadal axis may be more active in nonbreeding males than in non-breeding females. This hypothesis is consistent with anatomical and histological investigations mentioned above and reported by Jarvis (1991), which suggest that most non-breeding males produce mature gametes. Conversely, production of mature gametes does not normally occur in non-breeding females because ovulation is blocked (Faulkes et al., 1990a), and the ovaries of these females are under-developed and lack preovulatory follicles and corpora lutea (Kayanja \& Jarvis, 1971; Faulkes, 1990). Therefore, in physiological and anatomical terms, the socially-induced suppression of reproduction in non-breeding male naked mole-rats does not appear to be as complete as in non-breeding females, and these non-breeding males may be capable of fertilization should they mate.

The socially-induced block to ovulation in non-breeding female naked mole-rats appears to be due to reduced plasma LH concentrations arising from an inhibition of hypothalamic GnRH secretion (Faulkes et al., 1990b). Results from the present GnRH experiments suggest that some degree of suppressed hypothalamic GnRH secretion may also occur in non-breeding males. Like females, male naked mole-rats showed clear differences in their LH responses to different doses of exogenous GnRH. While breeders produced greater LH responses which did not decline at lower doses, non-breeding males showed a reduced $\mathrm{LH}$ response to 0.1 and $0.5 \mu \mathrm{g}$ doses of $\mathrm{GnRH}$, giving rise to significantly lower plasma $\mathrm{LH}$ concentrations $20 \mathrm{~min}$ after injection, compared to breeders (Fig. 2), and suggesting a lack of pituitary sensitivity to GnRH in the non-breeding males at these doses. Assuming that clearance rates of plasma LH do not differ between breeding and nonbreeding males, then, as with females (Faulkes et al., 1990b), this apparent lack of pituitary sensitivity may result from reduced concentrations of pituitary LH receptors, as a consequence of a lack of endogenous GnRH priming. In female rats, changes in sensitivity to $\mathrm{GnRH}$ are reflected in changes of pituitary GnRH receptor concentrations (Sandow, 1983; Clayton \& Catt, 1987). The fact that the higher dose of $1.0 \mu \mathrm{g}$ GnRH stimulated an $\mathrm{LH}$ response in non-breeders that was equivalent to that of breeding males, suggests that the pituitaries of non-breeders contained a similarly sized releasable pool of bioactive $\mathrm{LH}$.

Non-breeding males responded to repeated injections of $\mathrm{GnRH}$ in a similar way to non-breeding females (Faulkes et al., 1990b). Although 4 or 8 consecutive doses of $0.1 \mu \mathrm{g} \mathrm{GnRH}$ failed to reverse the lack of pituitary sensitivity to single injections at this dose (Fig. 3a), 4 consecutive hourly injections of $0.5 \mu \mathrm{g} \mathrm{GnRH}$ were sufficient to reverse the reduced pituitary sensitivity to a single injection of this dose (Fig. 3b). The ability of 4 priming injections of GnRH to overcome reduced pituitary sensitivity to GnRH in non-breeding males therefore suggests that reduced or impaired secretion of hypothalamic GnRH may result in reduced endogenous GnRH priming of the pituitary, compared with breeding males. Repeated administration of GnRH has been shown to increase pituitary LH content in hypogonadal male mice, a mutant which lacks endogenous hypothalamic GnRH (Charlton et al., 1983), and increase plasma LH levels in men with hypothalamic hypogonadism (Snyder et al., 1979).

Examples of the social suppression of reproduction in males of other species are less well documented than for females. Among rodents, perhaps the best example is the prairie deermouse, 
Peromyscus maniculatus bairdii, in which juvenile males are thought to be inhibited in their maturation by pheromones from adult males (Lawton \& Whitsett, 1979). Subordinate males in social groups of marmoset monkeys have their sexual behaviour disrupted by dominant males, although they are occasionally seen copulating with the dominant breeding female. Like non-breeding male naked mole-rats, these subordinate 'non-breeding' male marmosets had lower concentrations of plasma LH and testosterone, and reduced LH responses to GnRH, although spermatogenesis was not inhibited (Abbott, 1986). In the subordinate male marmoset, lower plasma testosterone concentrations may arise as a result of an alteration in the steroidogenic pathway by which androgens are synthesized (Sheffield et al., 1989).

These examples of reproductive suppression in male mammals are not so extreme as in the male naked mole-rat, in which most non-breeding males may never breed, despite having a lifespan which can exceed 15 years in captivity (Jarvis, 1991). Among other African mole-rats (Family Bathyergidae), the genus Cryptomys contains socially-living species which exhibit a behavioural and reproductive division of labour (Bennett, 1988). Colony sizes are considerably smaller than those of the naked mole-rat and may only number up to 12-22 individuals, in the case of $C$. hottentotus damerensis (Bennett \& Jarvis, 1988). Behavioural studies in captivity of $C$. h. hottentotus and $C . h$. damarensis have shown that, in these species, reproduction is limited to 1 male (Bennett, 1988, 1989). Histological investigations of non-breeding male $C$. h. damarensis have revealed that, as with non-breeding male naked mole-rats, spermatogenesis occurred in non-breeders, again making it difficult to relate the observed behavioural differences to functional changes, detrimental to fertility, in the reproductive tract.

While the present study showed that there were definite differences in the reproductive physiology of breeding and non-breeding male naked mole-rats, these differences were less clear-cut than in female naked mole-rats (Faulkes et al., 1990a, b). It is difficult to relate these differences in physiology in the male naked mole-rat to differences in fertility between breeders and non-breeders because spermatogenesis is maintained in both types of males. Because of the reduced plasma $\mathrm{LH}$ and testosterone concentrations, the development and secretion of accessory sexual glands may be reduced in nonbreeding male naked mole-rats, which may, in turn, have a detrimental effect on sperm viability in the ejaculate. A characteristic of the male hypogonadal mouse is a failure of accessory sexual tissue growth (Charlton et al., 1983).

The endocrine differences between breeding and non-breeding male naked mole-rats may be brought about by a suppression of reproductive function in the non-breeders, or may simply reflect that only breeding males are solicited for mating by the queen during oestrus and show active sexual behaviour.

We thank the NIDDKD, Baltimore, MD, USA and the National Hormone and Pituitary Program at the University of Maryland School of Medicine for the rat LH preparation (rLH-I-7) and GnRH; Miss F. E. Sherriff for assistance with some of the GnRH challenges; M. J. Llovett and the laboratory animal staff at the Institute of Zoology for care and maintenance of the animals; Professor A.P. F. Flint and Dr H. D. M. Moore for criticism of the manuscript; and Mr T. Dennett and Miss M.J. Walton for preparation of the figures. This work was supported by an MRC/AFRC Programme Grant, a project grant from the Wellcome Trust (D.H.A.), an SERC Research Studentship (C.G.F.), and grants from CSIR and UCT (J.U.M.J.).

\section{References}

Abbott, D.H. (1986) Social suppression of reproduction in subordinate marmoset monkeys (Callithrix jacchus jacchus). In A Primatologia No Brasil 2, pp. 1-16. Ed. M. T. De Mello. Sociedade Brasileira de Primatologia, Brazilia.

Abbott, D.H., Hodges, J.K. \& George, L.M. (1988) Social status controls LH secretion and ovulation in female marmoset monkeys (Callithrix jacchus). J. Endocr. 117, 329-339.

Bennett, N.C. (1988) The trend towards sociality in three species of Southern African mole-rats. Ph.D. thesis, University of Cape Town.

Bennett, N.C. (1989) The social structure and reproductive biology of the common mole-rat, Cryptomys 
h. hottentotus, and remarks on the trends in reproduction and sociality in the family Bathyergidae. $J$. Zool., Lond. 219, 45-49.

Bennett, N.C. \& Jarvis, J.U.M. (1988) The social structure and reproductive biology of colonies of the mole-rat, Cryptomys damarensis (Rodentia, Bathyergidae). $J$. Mammal. 69, 293-302.

Bonney, R.C., Wood, D.J. \& Kleiman, D.G. (1982) Endocrine correlates of behavioural oestrus in the female giant panda (Ailuropoda melanoleuca) and associated hormonal changes in the male. $J$. Reprod. Fert. 64, 209-215.

Brett, R.A. (1986) Ecology and behaviour of the naked mole-rat Heterocephalus glaber (Ruppell) Rodentia: Bathyergidae. Ph.D. thesis, University of London.

Brett, R.A. (1991) The ecology of naked mole-rat colonies: burrowing, food, and limiting factors. In The Biology of the Naked Mole-Rat, pp. 137-184. Eds P. W. Sherman, J. U. M. Jarvis \& R. D. Alexander. Princeton University Press, New York.

Charlton, H.M., Halpin, D.M.G., Iddon, C.A., Rosie, R., Levy, G., MeDowell, I.F.W., Megson, A., Morris, J.F., Bramwell, A., Speight, A., Ward, B.J., Broadhead, J., Davey-Smith, G. \& Flink, G. (1983) The effects of daily administration of single and multiple injections of gonadotropin-releasing hormone on pituitary and gonadal function in the hypogonadal (hpg) mouse. Endocrinology 113, 535-544.

Clayton, R.N. \& Catt, K.J. (1987) GnRH characterisation; physiology of regulation and the relationship to reproductive function. Endocr. Rev. 2, 186-209.

Faulkes, C.G. (1990) Social suppression of reproduction in the naked mole-rat, Heterocephalus glaber. Ph.D. thesis, University of London.

Faulkes, C.G., Abbott, D.H. \& Jarvis, J.U.M. (1990a) Social suppression of ovarian cyclicity in captive and wild colonies of naked mole-rats, Heterocephalus glaber. J. Reprod. Fert. 88, 559-568.

Faulkes, C.G., Abbott, D.H., Jarvis, J.U.M. \& Sherriff, F. (1990b) LH responses of female naked mole-rats, Heterocephalus glaber, to single and multiple doses of exogenous GnRH. J. Reprod. Fert. 89, 317-323.

Faulkes, C.G., Abbott, D.H. \& Mellor, A. (1990c) Investigation of genetic diversity in wild colonies of naked mole-rats by DNA fingerprinting. J. Zool., Lond. 221, 87-97.

Faulkes, C.G., Abbott, D.H., Liddell, C.E., George, L.M. \& Jarvis, J.U.M. (1991) Hormonal and behavioural aspects of reproductive suppression in female naked mole-rats Heterocephalus glaber. In The Biology of the Naked Mole-Rat, pp. 426-445. Eds P. W. Sherman, J. U. M. Jarvis \& R. D. Alexander. Princeton University Press, New York.

Fawcett, D.W., Neaves, W.B. \& Flores, M.N. (1973) Comparative observations on intertubular lymphatics and the organization of the interstitial tissue of the mammalian testis. Biol. Reprod. 9, 500-532.

Harlow, C.R., Gems, S., Hodges, J.K. \& Hearn, J.P. (1984) The relationship between plasma progesterone and the timing of ovulation and early embryonic development in the marmoset monkey (Callithrix jacchus). J. Zool., Lond. 201, 272-282.
Helwig, J.T. \& Council, K.A. (1979) SAS Users Guide. Cary SAS Institute Inc.

Hodges, J.K. (1986) Monitoring changes in reproductive status. Int. Zoo. Yb. 24/25, 126-130.

Hodges, J.K., Gulick, B.A., Czekala, N.M. \& Lasley, B.L. (1981) Comparison of urinary oestrogen excretion in South American primates $J$. Reprod. Fert . 61, 83-90.

Hodges, J.K., Cottingham, P., Summers, P.M. \& Yingnan, L. (1987) Controlled ovulation in the marmoset monkey (Callithrix jacchus) with human chorionic gonadotrophin following prostaglandin induced luteal regression. Fert. Steril. 48, 299-305.

Jarvis, J.U.M. (1981) Eu-sociality in a mammalcooperative breeding in naked mole-rat Heterocephalus glaber colonies. Science, $N Y$ 212, 571-573.

Jarvis, J.U.M. (1985) Ecological studies on Heterocephalus glaber, the naked mole-rat, in Kenya. Nat. Geographic Sci. Rep. 20, 429-437.

Jarvis, J.U.M. (1991) Reproduction. In The Biology of the Naked Mole-Rat, pp. 384-425. Eds P. W. Sherman, J. U. M. Jarvis \& R. D. Alexander. Princeton University Press, New York.

Kayanja, F.I.B. \& Jarvis, J. (1971) Histological observations of the ovary, oviduct and uterus of the naked mole rat. Z. Saugeteirk. 36, 114-121.

Lacey, E.A. \& Sherman, P.W. (1991) Social organization of naked mole-rat (Heterocephalus glaber) colonies: evidence for a division of labour. In The Biology of the Naked Mole-Rat, pp. 275-336. Eds J. U. M. Jarvis, P. W. Sherman \& R. D. Alexander. Princeton University Press, New York.

Lasley, B.L. (1985) Methods for evaluating reproductive function in exotic species. Adv. vet. Sci. comp. Med. $\mathbf{3 0}$, $209-228$.

Lawton, A.D. \& Whitsett, J.M. (1979) Inhibition of sexual maturation by a urinary pheromone in male prairie deer mice. Horm. \& Behav. 13, 128-138.

Sandow, J. (1983) The regulation of LHRH action at the pituitary and gonadal receptor level: a review. Psychoneuroendocrinology 8, 277-297.

Sheffield, J.W., O'Shaughnessy, P.J. \& Abbott, D.H. (1989) Social rank effect testicular steroidogenesis in male marmoset monkeys (Callithrix jacchus). $J$. Endocr. 123 (Suppl.) Abstr. 83.

Snyder, P.J., Rudenstein, R.S., Gardner, D.F. \& Rothman, J.G. (1979) Repetitive infusion of gonadotropinreleasing hormone distinguishes hypothalamic from pituitary hypogonadism. J. clin. Endocr. Metab. 48, $864-868$.

Sokal, R.R. \& Rohlf, F.J. (1981) Biometry: The Principles and Practice of Statistics in Biological Research, 2nd edn. W.H. Freeman and Company, New York.

Van Damme, M.-P., Robertson, D.M. \& Diczfalusy, E. (1974) An improved in in vitro bioassay method for measuring luteinizing hormone ( $\mathrm{LH})$ activity using mouse Leydig cell preparations. Acta endocr., Copenh. $77,655-671$.

Weir, B.J. (1967) Aspects of reproduction in some hystricomorph rodents. Ph.D. thesis, University of Cambridge. 